\title{
Effects of E-government framework usability: Jordan as a case study
}

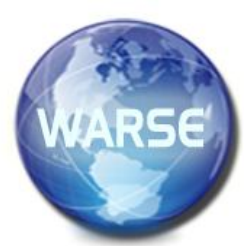

\section{ABSTRACT}

Governments are keeping up with the significant development in information and communications technology, because of the quality, speed and benefits of delivering services to users. Still, the success and failure of e-government services to achieve the expected objectives depend on some essential aspects, especially ease of use since services provide to the general public. This paper focuses on the usability of e-government services in Jordan as a case study. This paper, we study the status of Jordanian egovernment services to improve usability, to enhance the usability of services for better use and again successful Jordan egovernment. The approach used in this paper divided into the two-sample study. Firstly, twenty managers and officials working in the management and maintenance of Jordan egovernment projects. Secondly, 70 participants to test mandatory e-government services on the e-government portal in Jordan. The feedback result shows highlighted the main problems of the egovernment include: the lack of expert designers, the lack of feedback from end-users, the lack of public awareness of the user-friendly concept, the absence of clear frameworks, limited budgets, and the non-participation of end-users in the development of the service. The research also indicates that use on the Portal typically does not have a high degree of usability and that there is a lack of awareness of end-user needs and specifications. Also, the study found several problems with the user interface, the most important of which were problems with electronic payment, difficulty in dealing with errors and returning from them, and finally faced several issues related to non-application of usability criteria. Finally, the paper highlighted some recommendation to improve the usability of egovernment services in Jordan.

Key words: Usability, e-government, e-services, e-payment

\section{INTRODUCTION}

Government is a political system that manages and controls the country and society. It presents many services for stakeholders (citizens, visitors, organizations) and it seeks to explain the services with the highest quality by using the tools that help them to achieve the benefits with minimal effort and cost [1].

In the late of the last century, information and communications technology started to conquer the world because of its advantages such as accuracy and speed in data processing, preservation and recovering at low-cost which would save effort, time and much money which will benefit all. The technology is begin used by the government in all its work and services that presented for stakeholders like preservation, indexing, processing, exchanging and publishing it on the Internet, which is called E-government [2].

E-government is using information and communications of technology to improve the activities of public organizations. Egovernment aims to present the services for stakeholders with the highest quality, most comfortable and faster way.

There are three forms of E-government services: Firstly, to connect the public organizations to facilitate the connection. Secondly; people to know about taxes, in addition to obtaining a criminal certificate. Thirdly, regards to business facilitation their e-services such as the issuance of trade registry certificate and many services.

The most usability problems in e-government sites are aesthetic and minimalist design, recognition rather than recall, consistency and standards [3].

At the beginning of the nineties of the last century, the concept of E-government appears as a way for governments to use the most innovative information and communication technologies, mainly web-based Internet applications, to provide citizens and businesses with more convenient access to government information and services, to improve the quality of the services and to provide more significant opportunities to participate in democratic institutions and processes' [4].

At the beginning of this century, the governments began with providing their services electronically by converting these services from traditional form to the electronic format by using different strategies, like reengineering procedures for the presented services to depart from deadlock and the complexities of conventional services. In contrast, the primary purpose of the electronic conversion is to improve the level of providing services.

The purpose of automation as mentioned in the definition provides a better service for every field, and high-quality service with specific standards to achieve and the ability of a group of properties and substantial advantages to satisfy the requirement of clients [5].

Usability defined as the degree which software can use by specified consumers to achieve quantified objectives with several factors such as effectiveness, efficiency, and satisfaction.Usability is an essential factor in determining the success of an e-government project, and any e-government project should pay attention to its strategies for designing a website which is the cornerstone of the success of the project. The interfaces of the websites are one of the most important aspects of usability because it mediates the interaction and communication between the system and users. Usability should be the primary goal for front-end designers, and the websites 
Hamed Fawareh et al., International Journal of Advanced Trends in Computer Science and Engineering, 9(5), September - October 2020,8107 - 8114

should be satisfactory and have an excellent look to provide an enjoyable experience for the user.

\section{RELATED WORKS}

In recent years, there has been an increasing amount of literature on e-government usability studies for different countries and the effect on maintenance management of E-government projects. Emory studied the usability for VIAB project in India, the project that the government developed it for the engineering and science students to connect Internet and access to virtual laboratories certified on the browser.Twomillion experiments done on this application, the result was that when the lab designed there was no focus on usability, it seems that instructions of design and implementation of a program not enough to cover the basic standards of usability [6].

Islam et al.evaluate the usability of Bangladesh E-Government. The result of the study shows that the e-government sites of Bangladesh suffer from severe weakness of usability. Also,the development committeedoes not consider the usability from the beginning do not followa standard and specific instruction [7]. Almarashdehuses the way of heuristic to evaluate the usability of Malaysia e-government services of smartphones; five experts evaluated the services. The result was good, but there were some problems like sizes page was not suitable with a mobile screen, this study for the experts, it did not take the satisfaction and the acceptance of the users [8]. Thisresearchevaluates the usability of the Malaysian ministry of education, by providing an experimental search for a set of quality features related to usability certified by ISO/TEe 25010. The result of this research showsgoodusability except for the property of effectiveness.

Gopinathstudy the usability ofSrilanka e-government sites. The extent to which these sites are committed to usability and accessibility standards and analysis tools such as PowerMapper, Pingdom tool, WAVE, google page speed insight. The researchfound a problem in usability, such as the user cannot manage to complete the required task[9].

Acosta and Vargas study twenty competitively E-government websites according to the highest performed quality for the users, especially disabled people in terms of accessibility. They evaluate the accessibility of these websites by compatibility with the Web Content Accessibility Guidelines 2.0.The result shows the websites do not achieve the required level to commit with the accessibility standards. The research advised the developers of egovernment sites to use the WEAG .2.O guide as a reference point. This matter is necessary to enhance the services performed for ordinary and disabled people, resulting in substantial obstacles to many users who relate to there is no effort in the basic rules to take into account all categories of society.

[10].

KAMAU evaluate E-government of Kenya (iTax), the purpose of the study is to assess the usability of iTax, especially user experiment from the public. The evaluation framework is containing five indicators that measure five factors, namely: accessibility, citizen engagement, transparency, and responsiveness. The interviews used with evaluating and consider the most appropriate means to the user experiment. The website records a big failure in achieving usability and public value.The website needs to improve the user interface, the massages that appear to the user and the user understandability. The developer doesn't use usability standards [11].

\section{THE USABILITY OF E-GOVERNMENT SERVICES FROM THE OFFICIALS POINT OF VIEW}

The official view relies on an administrative questionnaire circulated to the Department of Officials. Responsible departments for the e-government platform and the administration

of services for all institutions in the Ministry of Services Leadership and Digital Economy. It presumes that the study findings will apply to current knowledge by clarifying some of the keys factor leading to the improvement of the study.

The study organizes sections; the first section dealt only with the demographic composition, professional status, degree of participation and experience of E-government services in Jordan. The second section dealt with understanding issues of Egovernment services and usability, and finally, factors affecting the usability of E-government services in Jordan. The questions based on a Likert scale ranging from 1-to-5, where one is for powerfully disagree, and five is for intensely agree [12].Since the purpose of this study is to verify the administrative level of usability of current e-government services in Jordan, our sample focused on the views of professionals responsible for the management and maintenance of the e-government site, the supervision of electronic services and the e-government project in Jordan.

For the study goals, we set up 20 questionnaires. The questioners distributed in the E-government department / Ministry of Digital Economy and Leadership. All participants pay attention to the tasks in Jordan's e-government department. The department includes the stream of project management, system engineer, quality control, system engineer and analyst of industry. Also, because of the number of workers employed in the Egovernment department, we note that the sample number is not high. The study needs the consent of the targeted individuals to perform the research, and the researcher

must clarify the subject matter and its role to the participants and participate willingly in the study. Also, the Mean of the survey explains to all staff and officials involved in completing the questionnaire and permission was obtained to use the data collected as part of the study while ensuring that the data is confidential

[13].The participant's ageis between 22 and 65 years, and the majority $(90 \%)$ is between 22 and 40 years. $45 \%$ of the participants were males and 55\% females.All participants in the questionnaire had a bachelor's degree $(95 \%)$ in disciplines such as computer science, computer engineering, software engineering, computer and management information systems, and only $5 \%$ had a postgraduate degree.20\% of the participants in the E-government project have worked for more than four years, $55 \%$ for two to four years, and $25 \%$ for one to two years. The roles of participants changed from employee to employee, and their positions varied from business analyst, system engineer, quality control, quality assurance, infrastructure engineer, OPS engineer.

\subsection{The Outcomes}

It was clear that $85 \%$ of respondents saw usability as essential to the success or failure of E-government projects, while $15 \%$ of respondents did not know much about the usability. $35 \%$ of the system users believed the current site was somewhat confusing to follow up, and it was not easy to navigate. Besides, $40 \%$ of 
feedback received from users was not happy about the appearance of the site. Also, 55\% of system users believed that the website does not have an effective search to facilitate access to information. The complexity of accessing facilities was $50 \%$. The e-payment system's effect is just $50 \%$. The e-payment reliability is $45 \%$. Finally, $45 \%$ of the fundamental skills that help them execute what they want is poor.

Table 1: Paying Attention to End-users

\begin{tabular}{|l|l|l|l|l|l|}
\hline & $\begin{array}{l}\text { Yes, } \\
\text { Possibly } \\
\text { yes }\end{array}$ & $\begin{array}{l}\text { Not } \\
\text { Sure }\end{array}$ & $\begin{array}{l}\text { No, } \\
\text { possibly } \\
\text { no }\end{array}$ & Mean & SD \\
\hline $\begin{array}{l}\text { Paid attention to the end user } \\
\text { requiremejts before establishing the E- } \\
\text { government systems. }\end{array}$ & $\mathbf{3 0 \%}$ & $55 \%$ & $15 \%$ & 2.650 & 0.9881 \\
\hline $\begin{array}{l}\text { Surveyed the requirements of end user } \\
\text { after launching E-government system for } \\
\text { further improvement. }\end{array}$ & $60 \%$ & $20 \%$ & $20 \%$ & 2.250 & 1.1642 \\
\hline
\end{tabular}

After asking the Participants about their views on the significant challenges of making systems accessible for end-users Table ( 5), $60 \%$ of the participants thought that the shortage of designers specializing in e-government services and also the lack of feedback from end-users were among the most significant challenges that could impede the usability of e-services,

Participants concentrated on budget shortfalls as a significant cause of $45 \%$, lack of understanding of the usability principle $55 \%$. The result shows that e-government faces the same issue as coherent structure across and supported programs, contrary to previous studies. Finally, the end-user does not participate in the development of primary-level services by $30 \%$.

Based on the study results and analyze the previous works,as shown inTable (2). The mean values ranged between 2.2 and 2.7, the challenges that hinder the development of government systems that are usability are similar in proportions, and this indicates that focus should be on all challenges And work to overcome them, and also the values of the standard deviation ranged between 0.8 and 1.2. We notice a little difference between the results indicates the homogeneity of the resulting data.

Table 2: Challenges of Making Systems Usable for End-User

\begin{tabular}{|l|l|l|l|l|l|}
\hline & $\begin{array}{l}\text { Strongly } \\
\text { agree, } \\
\text { Agree }\end{array}$ & Not sure & $\begin{array}{l}\text { Strongly } \\
\text { disagree, } \\
\text { Disagree }\end{array}$ & Mean & SD \\
\hline $\begin{array}{l}\text { Lack of awareness of usability. } \\
\text { Not involving end-user in the } \\
\text { stage of design. }\end{array}$ & $30 \%$ & $\mathbf{2 5 \%} \%$ & $20 \%$ & 2.450 & 1.1910 \\
\hline Lack of budget & $45 \%$ & $40 \%$ & $15 \%$ & 2.650 & 0.9881 \\
\hline $\begin{array}{l}\text { Lack of feedback from end- } \\
\text { users. }\end{array}$ & $60 \%$ & $20 \%$ & $20 \%$ & 2.500 & 1.0000 \\
\hline $\begin{array}{l}\text { Lack of expert systems } \\
\text { designers. }\end{array}$ & $60 \%$ & $30 \%$ & $10 \%$ & 2.300 & 1.0809 \\
\hline Management problems. & $40 \%$ & $45 \%$ & $15 \%$ & 2.700 & 0.8013 \\
\hline $\begin{array}{l}\text { Lack of a general framework } \\
\text { for services. }\end{array}$ & $45 \%$ & $45 \%$ & $10 \%$ & 2.550 & 0.8256 \\
\hline
\end{tabular}

The results also showed that about $30 \%$ of respondents did not take into account end-user requirements before the creation of government systems Table (1); while 15\% did so. Moreover, after the launch of the E-government system, only $20 \%$ of respondents met end-user requirements for further developments The outcome of the questionnaires distributed about egovernment resources in Jordan shows that the e-government resources use is increased and improved significantly. The result of the questioners about the e-government resources indicates that the usage of e-government resources s increased essentially and reinforcement in Jordan. Based on analyzing the work, as shown in Table 3, theimpact includes: existing government system guideline and specifications are transparent with $70 \%$, user benefit and consumer used. For the qualifying workers, the same number, followed by $60 \%$ for end-users.

The guideline and requirements for the currentgovernment frameworkare $70 \%$ clear and benefit to the user used. The same percentage for theemployeeeligible, followed by $60 \%$ for endusers. The general framework for services, increased by $55 \%$ in the budget. Based on analyzing the results depends, as shown in Table (3) the Mean values ranged between (2.1-2.4).The factors contribute to increase and improve infrastructure.Developing a government structure has an easy-to-use property that is close to proportions, and this guides the developer to concentrate on promoting and intensifying and varying between (0.9-1.3) regarding the value of Standard Deviation.

We notice that the dispersion between the data is close as we know whenever the percentage of distribution between the values indicates that the homogeneity increases.

Table 3:Improving and Increasing Usability

\begin{tabular}{|l|l|l|l|l|l|}
\hline & $\begin{array}{l}\text { Strongly } \\
\text { agree, } \\
\text { Agree }\end{array}$ & Not sure & $\begin{array}{l}\text { Strongly } \\
\text { disagree, } \\
\text { Disagree }\end{array}$ & Mean & SD \\
\hline Trained staff. & $70 \%$ & $15 \% \%$ & $15 \%$ & 2.100 & 1.0712 \\
\hline More budget. & $55 \%$ & $30 \%$ & $15 \%$ & 2.400 & 0.9947 \\
\hline Involving end-users. & $60 \%$ & $20 \%$ & $20 \%$ & 2.350 & 1.0894 \\
\hline Clear guidelines and standards. & $70 \%$ & $10 \%$ & $20 \%$ & 2.200 & 1.3611 \\
\hline A general framework for service & $60 \%$ & $25 \%$ & $15 \%$ & 2.400 & 1.0454 \\
\hline
\end{tabular}

The result shows that the most critical factors that help to develop usability systems at the highest rates trained staff and clear guidelines and standards.

\subsection{Discussion}

In developing and building up E-government services, very much attention should be given to the usability, since it is of great importance to the success of E-government projects. The view of E-government officials in Jordan and this is certain that service interfaces are the link between citizens and e-services. If these interfaces are easy to deal with, understand and attract them, all this reflect on citizens with satisfaction, and this is proof of the success of government services.

Based on the questionnaire and the views of the participants, it is easy to find the usability of e-government services. There are also some difficulties in developing the usability of e-services, ranging from material and administrative problems to technological problems, as well as difficulties in creating specialized skills in the creation of government services in Jordan.

Each government institution in Jordan is responsible for the process of electronic transformation. Also, the operation of its services on its own, under the supervision and follow-up of the basic instructions of the Ministry of Digital Economy and Leadership's e-government department, and the majority of government employees work in the technical support role.

They do not have sufficient E-government expertise, especially in the development of a usability service. So, the lack of experts in the development of the usability services considers one of the most challenges and the biggest ones, as noted in the questionnaire participants.

It is also no less important than taking the feedback of users about the e-services. This point is indicative of the success or failure of the service and finds the problems not apparent to the services development team that stands in the way of the usability. 
The concept of usability is broad, and there is a range of standards that must be adhered to when designing a system. These standards vary by system type, purpose, target group, and many things that we must observe [6] which wants to develop government services that must be sufficiently aware of the environment, infrastructure, society, and culture because government services target to the general public. Government officials said, awareness of usability standards constitutes a significant challenge for designing easy systems.

The development of electronic usability services is complicated and has many challenges; the first challenge is the financial, i.e. the budgets for the development of services or the service itself, which are a significant obstacle. The second challenge is the development team must create a service within a given budget that is not within the requirements expected.

A unified framework adopted by the government in the development of its services for all institutions may greatly facilitate the task by the existence of a set of steps, rules and laws that will thwart the development process, as each organization adopts a different framework for its services.Administrative problems is one of the difficulties and obstacles facing the development of the usability of services, which are directly or indirectly affected by a difference between the management team or the continuous change of departments and many reasons.

The final challenge was the end-users non-participation in the development of electronic services in the initial stages of design. We know that the presence of end-users in the development process can build hurdles and mistakes. The experts as professionals and practitioners will not find, and the early detection of any issue will generate a lot of effort, time and expense, as we know at the end of the project.

\section{ASSESSING THE USABILITY OF E-GOVERNMENT SERVICES FROM THE END-USER POINT OF VIEW}

In this study, some important data are analysis technically. Table (4) presents the obtained means and standard tested categories of Search and Accessibility, Navigation, Help, Error and Recovery, E-Payment, Appearance, and public Satisfaction.

The study outcome shows that the main problem of the user is the interface. For example, when using the E-government services, which was the electronic payment process, the percentage ofuser problems in the user interface is $42.9 \%$.Then the errors and backing point are $30 \%$, followed by the general appearance of $24.9 \%$, then the help of $22.9 \%$. Finally, the navigation followed by the search and reached rates of $17.1 \%$ and $15.7 \%$ respectively.

Based on the resultdiscussionand analyzing the previous data as shown in the Table (4), the mean values ranged indicates that the level of usability e-government systems in Jordan is approximately on average with a value between (2.513.10).Also, the standard deviation ranged between (1.02-1.60), As we see that the dispersion between the data is close to the values, as we know the less the dispersion ratio between the weights, this indicates an increase inhomogeneity.
Table 4: Problems Encountered by Users.

\begin{tabular}{|c|c|c|c|c|c|}
\hline Item & $\begin{array}{l}\text { Strongly } \\
\text { disagree, } \\
\text { Disagree }\end{array}$ & $\begin{array}{l}\text { Not } \\
\text { sure }\end{array}$ & $\begin{array}{l}\text { Strongly } \\
\text { agree, } \\
\text { Agree }\end{array}$ & Mean & SD \\
\hline $\begin{array}{l}\text { Search and Accessibility } \\
\text { How to assess the ease of searching and access to } \\
\text { services? }\end{array}$ & $15.7 \%$ & $47.1 \%$ & $37.2 \%$ & 2.70 & 1.026 \\
\hline $\begin{array}{l}\text { Navigation } \\
\text { How easy it is to navigate pages and find the } \\
\text { information you need? }\end{array}$ & $17.1 \%$ & $41.4 \%$ & $41.4 \%$ & 2.67 & 1.046 \\
\hline $\begin{array}{l}\text { Help } \\
\text { Are there multiple ways to help you get the job } \\
\text { done easily? }\end{array}$ & $22.9 \%$ & $30 \%$ & $47.1 \%$ & 2.73 & 1.227 \\
\hline $\begin{array}{l}\text { Error and Recovery } \\
\text { How easy it is to deal with errors and retum from } \\
\text { them and to complete the service? }\end{array}$ & $30 \%$ & $24.3 \%$ & $45.7 \%$ & 2.84 & 1.163 \\
\hline \multicolumn{6}{|l|}{ E-Payment } \\
\hline $\begin{array}{l}\text { Have you had problems with your electronic } \\
\text { payment } \\
\text { Appearance }\end{array}$ & $42.9 \%$ & $11.4 \%$ & $45.7 \%$ & 3.10 & 1.608 \\
\hline $\begin{array}{l}\text { How satisfied are you with the language, font, } \\
\text { colors and overall appearance of the site }\end{array}$ & $24.3 \%$ & $25.7 \%$ & $50 \%$ & 2.60 & 1.345 \\
\hline \multicolumn{6}{|l|}{ Overall Satisfaction } \\
\hline $\begin{array}{l}\text { Will you use the services again and recommend } \\
\text { them }\end{array}$ & $22.8 \%$ & $21.4 \%$ & $55.7 \%$ & 2.51 & 1.316 \\
\hline
\end{tabular}

\subsection{Discussion}

Most users of E-government services in Jordan face a problem in the e-payment process, the most important of which is that electronic services and e-payment services are modern and widespread in Jordan. Therefore, the electronic financial culture of the people in Jordan is somewhat weak. Because the financial matters, in general, are sensitive and should be carefully dealt with, no one can share his financial data and ask for someone's help in accomplishing his financial matters. We also know that there are people who cannot deal with ATM despite its ease, and it remains somewhat confusing. Regarding the securityservices issues, in terms of electronic financial, people generally follow different security policies such as e-mail, SMS, secret codes and others, in addition to many steps that some can consider complicated and tedious. Others may view them as brutalasolder people or those who deal with these services for the firsttime and do not receive e-service training.

The problem is not only that government services and payment can have different means of assistance, but it does not show the user how to use banking applications. Here is another problem that can be solved easily in cooperation with governments and banks by holding mandatory e-awareness workshops with some incentives and distributing awareness-raising publications in electronic financial services and other means of awareness.

Although there is an illustrative video of the electronic payment method for each service, this service is still a real problem, and we believe that this is due to some reasons. First of all, lack of experience and awareness of how to design the mechanism of Egovernment services usability. As we have seen in the previous chapter, E-government officials have seen the most critical challenges facing governments in designing the usability of electronic services that have come with the highest lack of sufficient expertise by $60 \%$, followed by a $55 \%$ shortage of standards and guideline.

The Portal and notice that there is a small button to watch a video of some services, which shows the electronic payment mechanism and complete the service, but the video icon does not express what is inside, and also these illustrations do not exist in other languages than Arabic. If you enter the required service, you cannot quickly return to the video and return from the started point.

In the previous questionnaire, we also noted that the percentage of those with scientific certificates is $88.6 \%$, and the youth category is $94.3 \%$. They use the Internet daily by $100 \%$, and the problem rate was very high.

The user interfaces other problems, which are errors and omissions, appearance, general satisfaction with services, means 
of assistance, navigation, and finally search and access. The justification for this study is to focus on the lack of knowledge and usability understanding nature for the e-government services, which can be overcome by the establishment of a standard structure for all state institutions' services.

\section{THE PROPOSED USABILITY MODEL}

The findings of the previous chapters, which focused on the views of professionals responsible for the management and maintenance of Jordan's E-government project as well as on the ideas of end-users, pointed out that problems were facing the possibility of using E-government systems in Jordan. Consequently, there was a need to focus on building a road map or proposing a solution to improve the utilization of Egovernment systems in Jordan. Therefore, this section presentsa model to enhance the use of E-government systems in Jordan. This model emerged after studies had revealed several issues concerning access to E-government systems. The expert evaluation required to validate the model conducts before the final model adopted. The proposed model believed to contribute to the existing knowledge pool by proposed a road map that would help improve the utilization of E-government services in future services. It is worth mentioning that the proposed model is useful not only from the perspective of enhancing the Jordanian context but also from similar contexts like other developing countries and Arab countries in particular that may share the same situation.

\subsection{Managers' Study}

In developing and building up E-government services, a lot of attention should be given to the usability, since it is of great importance to the success of E-government projects. This view of E-government officials in Jordan and this is certain that service interfaces are the link between citizens and e-services. If these interfaces are easy to deal with, understand and attract them, all this will reflect on citizens with satisfaction, and this is proof of the success of government services. However, it is easy to find the usability of E-government services, based on the feedback of the distributed questionnaire. Some difficulties hinder the construction of usability of e-services, which are different from physical and administrative problems, technical problems and problems in creating specialized competencies in the development of government services in Jordan.

The government faced some difficulties that will list in a sequence from the most difficult to the least. The first was the lack of experts in designing the usability of E-government services and the lack of adequate feedback after the service launch to take user opinions and develop them, then the lack of awareness of the standards of usability by direct institutional officials. The budget has dramatically affected the quality of services. In particular, the administrative operation difficulties are 1. Sharing a management process is a weakness, the Egovernment project2. the incoherence of the institutions to a large extent of the enjoyment of all services 3. the nonparticipation of the end-user in the design of primary-level services.A range of factors that could positively support the design process of services in a usability manner. First, usability standards are clear to everyone and understood, then training the team involved in the development process, end-user participation in the development process, a unified framework for service development, as well as budget increases, and finally, interinstitutional linkage [22].
Managers and administrators believed that the most critical problems faced by users while using E-government services are mostly due to the difficulty of searching and accessing services and the difficulty of e-payment, hence the problem of aids and skills problem. There is another problem with the navigation and finally, the lack of good feedback from users.

\subsection{Users' Study}

The study is used as a user testing method, as this considered to be essential and a useful way to give direct information about end-users interaction with the interfaces.

The purpose of the user study was to build a clear overview of the use of E-government services in Jordan. We achieved through an investigation of design aspects that have affected the success of E-government services in Jordan from the perspective of end-users. The measurement of the study included navigation, search, customization, appearance and general satisfaction.

Following an analysis of the results, the lack of clear guidelines on usability has found to harm the extent to which electronic government services utilized in Jordan. The problem of electronic payment was also considered the most significant user interface problem.

\subsection{Determine Requirements}

Based on the two previous studies, there were a set of requirements for building a proposed model for improving ease of use of the E-government services in Jordan and we will list them below in the form of points, which will be the basis of the model to be proposed:

- Management "is a distinct on-going process of allocating inputs of an organization (human and economic resources) by typical managerial functions (planning, organizing, directing, controlling, achieve stated objectives, viz., the output of goods and services desired by its customers (environment)" [14].

- Framework "is a particular set of rules, ideas, or beliefs which you use to deal with problems or to decide what to do" [3].

- Standards "are something considered by an authority or by general consent as a basis of comparison; an approved model" [15].

- E-payment "is a way of making transactions or paying for goods and services through an electronic medium, without the use of checks or cash. It's also called an electronic payment system or online payment system" (Mitchell, 2005).

- Awareness "knowledge and understanding that something is happening or exists" [16].

- Experiences "are knowledge or practical wisdom gained from what one has observed, encountered, or undergone" [17].

- Budget "is a financial plan for a defined period, often one year. It may also include planned sales volumes and revenues, resource quantities, costs and expenses, assets, liabilities and cash flows" [18].

- User involvement "refers to the process by which people who are using or have used a service become involved in the planning, development and delivery of that service" [19].

- User feedback "is all the information you get from your customers about whether or not they are satisfied with your product or service" [20].

We categorize thee-government,as shown in Figure 5. 
Hamed Fawareh et al., International Journal of Advanced Trends in Computer Science and Engineering, 9(5), September - October 2020,8107 - 8114

Table 5: Classification of Requirements.

\begin{tabular}{l|l}
\hline Category & Sub-category \\
\hline Human Resources & Standards, Experiences, Awareness \\
\hline Management & Management, Budgets, Framework \\
\hline User & User Involvement, User Feedback \\
\hline E-Payment & New technology \\
\hline
\end{tabular}

\section{THE PROPOSED MODEL FOR PUBLISHING USABILITY} SERVICES

Based on AlFawwaz [5], the model addressed a range of problems regarding the usability of E-government services such as framework, management, experience, user participation in design and development, and finally awareness of usability standards. But there was a problem with the proposed model as mentioned earlier, leading us to present a new model that addresses issues not addressed in the previous model:

- Based on the results of the previous study, e-payment in eservices is one of the biggest challenges facing users. This issue did not address at earlier research. e-payment or any new technology that could affect usability. When designing the form, one must take into account all elements that could affect the usability so that all problems and sustainability are covered.

- The specific budgets for the development of electronic services are a significant burden, and the emphasis is on the development of services within budgets rather than within quality standards. The point not emphasized and how to resolve them in the proposed model. On the contrary, the Arbitration Commission costs enormous amounts of material to governments.

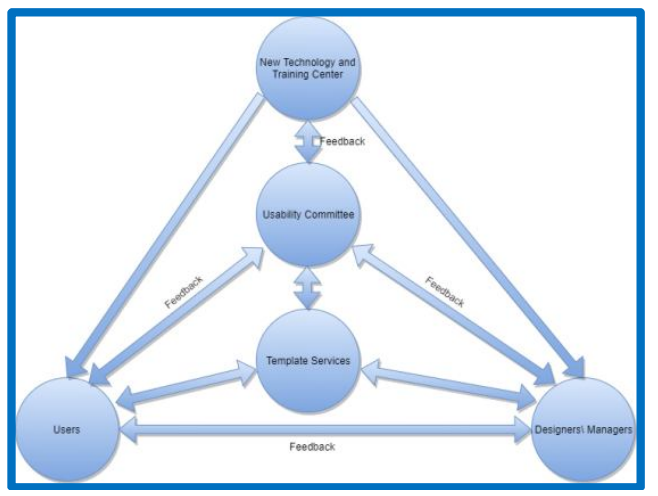

Figure 1: The Usability Proposed Model for JordanE-government.

- In terms of experience and enhance awareness of usability concepts and standards, this goal achieved by the usability committee according to the proposed model. However, we believe that it is challenging to work on committees, training and continuous awareness regarding the usability criteria for each service that individually developed and that negatively affects budgets. The costs of committees and exercise are very high.

The E-governmentservices usability model is an outline or a roadmap that will provide a guide on how to have usable Egovernmentservices in Jordan. The model has five components: Services manager and designer, Users, Template services, New Technology and Training Center, and Usability Committee Figure (1).

The following explains the roles of the components and demonstrates how they contribute to the model.

\subsection{New Technology and Training Center}

The presence of a study centre that connected to modern technology and the training for managers, designers and users, is one of the most essential and primary factors in the development process of electronic government services and to make it easier to use. This factor presents a set of services to help with the development process, and it is as follows:

- The study of modern technology and its effect on the development of electronic governmental services, the study of environment and culture of the country, the ability to involve it in the electronic government services and the user's ability to learn and use it efficiently and correctly.

- Develop usability standards which will be suitable and will achieve a comfortable use of the electronic services for the users.

- Train managers and developers on how to improve usability services and supply them with the standards that must follow when developing.

- Users problems

- Training the users and keeping them aware of any moderate technology in different ways that are compatible with their abilities.

\subsection{Services Manager and Designer}

The factors that are related to the ease of use for the egovernmental services includes the managers and designers who work in the development of the electronic service, and this factor is present in the proposed model to develop electronic government services that are usability, and their role is as follows:

- The designers construct templates/models for the electronic services depending on the experience and training that they got from the training centre.

- The designers also take instructions and notes from the ease of use committee regarding the templates that they are developing.

- They also take some notes and problems from the users through a shared process to develop templates, and they work on solving it as much as possible.

- The managers supervise the constructing process of the services and coordination templates.

\subsection{Users}

It is imperative to involve the end-user in the service's templates constructing process since these templates must be ata high level of the ease of use. There has been an essential role for the enduser in the proposed model. The user gets involved in the development process by determining the requirements and testing the templates and defining the problem faced. And this a repeated process until we reach a service template that suites all users categories regarding the ease of use.

\subsection{Usability Committee}

The experts are very highly qualified, skilled and experienced people regarding the ease of use [21]. Therefore, they can submit proposed suggestions and recommendations that are accurate and efficient and enhance the ease of use of services, consequently enhance the full experience for the user. In the proposed model there has been a need to build up the comfort of use committee that is consisting of a group of specialized experts in developing electronic governmental services that are usability, and their role comes in various subjects:

- Working with managers, designers and users to guarantee developing services template and to achieve all standards of the ease of use. 
Hamed Fawareh et al., International Journal of Advanced Trends in Computer Science and Engineering, 9(5), September - October 2020,8107 - 8114

- It is working on solving the problems that face the users during the development process and giving notes and instructions for the designers.

- Contact and participating with modern technology

- We are approving the final service's templates before launching them.

\subsection{Validation}

To verify the proposed model, we review and evaluate the model by three groups. The first group is a specialist (10 participants). This group represents the opinions of professionals responsible for managing the E-government project in Jordan. The second group consists of technical professionals (computer engineers, people with computer background, web administrators, designers, and technical managers) (10 participants). The third group of academics formed to reflect a broader view of the model (10 participants). Finally, 30 participants have assigned to the overall assessment. Beforethe groups listed review and evaluate, the draft questionnaire will draft based on the model. They will then be triedand refined in the final questionnaire.

The survey results will be analyzed using the 5-point Likert standard. When all participants finish, the questions will be coded and replied to be analyzed using the SPSS program.

\subsection{Analysis and Outcomes}

In our study, $70 \%$ of the participant males, while $30 \%$ offemales. Regarding the self-declared level of familiarity with systems: Excellent: 3.3 ,Good:40\% andPoor: $6.7 \%$. Years of experience:less than two years: $26.7 \%, 2-5$ years Experiencein their fields:20\%,5-10 years Experiencein their areas:26.7\%, more than ten years: $30 \%$.

Based on the obtained results, it noted that the means varied between 4.46 and 4.26 for the related questions. It was clear that the assessors believed that the model is useful and applicable to accomplish usable systems in Jordan. It covers a range of essential usability issues about E-government services highlighted in the conducted studies.

Also, the results pointed out that the assessments' average for the three groups is of a similar range in values. The Mean for Egovernment specialists group is 4.7 (SD: 0.13), and the Mean for a technical group is 4.15 (SD: 0.77) while the Mean for researchers group is 4.3 (SD: 0.59). Moreover, it has noted that the obtained results are Greater than the mean scale, which is 4 . Weconsider this result a good sign from the participants toward the proposed model generally. However, this does not grant an accurate assessment.

\section{CONCLUSION}

The study conducted to assess the usability of Jordanian Egovernment systems to contribute to the provision of accessible electronic government services and a successful government project in Jordan.

Based on the outcomes of the various tasks performed in this research work, the following conclusions have reached.

Based on a review of previous literature and studies, we find a weakness in the usability of E-government services in Jordan.Many research has conducted on the usability of Egovernment services in developing countries, and a variety of models have proposed to solve this problem as standards,budgets, general framework,experience,management, focus on aesthetic, and user participation. But some obstacles are to be overcome, and others emerge as technology progresses. So it may decide that further research into usability assessments for
E-government is necessary.

To achieve the usability of e-government systems in Jordan by conducting the first studies from the end-users, managers and officials point of view based on the results obtained; a proposed model created to help design usability systems.

The results show that $43 \%$ of users have a problem in using the E-payment system.

Furthermore, the result shows that $30 \%$ of the user have errors during the use of the e-government system. Users find out the appearance is not good; the percentage is $24.3 \%$. $22.9 \%$ of the user-facing a problem with help, and $22.8 \%$ of the users are not satisfied with the system. Some users encountered trouble in the process of searching for services and access by $17.1 \%$ and navigation by $15.7 \%$.

The second study focused on verifying the usability of egovernment systems in Jordan from the viewpoint of officials in the e-government project to determine the root causes of the usability problem.

The result highlighteda set of challenges hindered the usable development includes $60 \%$ the lack of experts in that field and the lack of feedback from end-users and 55\% a lack of awareness in the concepts of usability of developers, followed by limited budgets and lack of A general framework with a rate of $45 \%$, management problems at a rate of $45 \%$, and finally, the end-user not participating in the design stages $35 \%$.

Furthermore, the set of factors that help improve and increase the usability of e-government systems include clear guideline andstandards and training work for the development team: 70\%, the end-user participation in the initial stages of design and the presence of a general framework: $60 \%$, increase in Budgets: $55 \%$.

The results analyzed and identified the most critical factors that contribute to building electronic government systems which include easy to use, overcome the challenges and problems.These factors classified into four main groups to facilitate the process of dealing with them, and they are as follows: management factors, human resources, new technology and finally end-users Or the beneficiaries of those systems.

A model has built that consists of five essential criteria that have been determined based on the previous requirements and classifications, namely the usability committee, managers and designers, users, new technology and training centre, and the template services.

These elements interact with each other to achieve usable services, through three levels at the same element level, the interaction of two or more factors, and at the model level.

The proposed model evaluation showed that the vast majority of residents (e-government, technical, and academic) favour the proposed model, $88 \%$ they see it as a significant contributor to help raise awareness and solve critical challenges highlighted in the main objective of the study.

Finally, this research project has contributed to some key findings regarding the usability of E-government services in general and Jordan in particular. The proposed road map can play a crucial role in usability e-services.

\section{REFERENCES}

[1] . Brogan. (2018)"The political system by which a country or community administered and regulated", (Doctoral dissertation, University of Kent).

[2] . Heeks, R. (2010). Do information and communication technologies (ICTs) contribute to development? Journal 
of international development, 22(5), 625-640.

[3] . Horváth, V. (2019). Project management competencedefinitions, models, standards and practical implications. Vezetéstudomány-Budapest Management Review, 50(11), 2-17.

[4]. Fang, Z. (2002). E-government in the digital era: concept, practice, and development. International Journal of the Computer, the Internet and management, 10(2), 1-22.

[5] . AlFawwaz, B. M. (2012). Evaluation of eGovernment websites usability in Jordan. Brunel University School of Engineering and Design $\mathrm{PhD}$ Theses.

[6] . Emory, J. (2018). Usability Analysis of Virtual Labs. Paper presented at the 2018 IEEE 18th International Conference on Advanced Learning Technologies, USA.

[7]. Islam, M. N. (2017). Assessing the Usability of eGovernment Websites. Paper presented at the International Conference on Electrical, Bangladesh.

[8] . Almarashdeh, I., \&Alsmadi, M. (2016, December). Heuristic evaluation of mobile government portal services: An experts' review. In 2016 11th International Conference for Internet Technology and Secured Transactions (ICITST) (pp. 427-431). IEEE.

[9] . GopinathSittampalam, et al. Usability and accessibility analysis of selected government websites in Siri Lanka TENSYMP IEEE Conference May 2016

[10]. Acosta-Vargas, P. (2017). Quality Evaluation of Government Websites. Paper presented at the 978-15090-4830-4/17/\$31.00 (C) 2017 IEEE.

[11]. KAMAU, G. (2016). E-government Websites User Experience. Paper presented at the IST-Africa 2016 Conference Proceedings, Africa.

[12] . Edmondson, D. R. (2005). Likert scales: A history. Paper presented at the Proceedings of the 12th conference on historical analysis and research in marketing (CHARM).

[13]. Yahaya N., FawarehHamed, "Slicing object-oriented programs".Malaysian Journal of Computers, Vol 14, No 2, 2001.

[14]. Kupersmith, J. (2008). Is usability the new BI? Technology in libraries: Essays in honour of Anne GrodzinsLipow, 73-86.

[15] . Zahariadis, N. (2019). The multiple streams framework: Structure, limitations, prospects Theories of the Policy Process, Second Edition (pp. 65-92): Routledge.

[16] . Tan, M. (2004). E-payment: The digital exchange: NUS Press.International Journal of Information Systems and Social Change (IJISSC), 5(1), 47-67.

[17]. Apel, K. (2014). A comprehensive definition of morphological awareness: Implications for assessment. Topics in Language Disorders, 34(3), 197-209.

[18] . Morrison, L. J. (2006). A Matter of Definition: Acknowledging Consumer/Survivor Experiences through Narrative. Radical Psychology: A Journal of Psychology, Politics \& Radicalism, 5.

[19] . Balseiro, S., Kim, A., Mahdian, M., \&Mirrokni, V. (2017). Budget management strategies in repeated auctions. Paper presented at the Proceedings of the 26th International Conference on World Wide Web.

[20] . Barki, H., \&Hartwick, J. (1994). Measuring user participation, user involvement, and user attitude. MIS quarterly, 59-82.

[21] . Fawareh, H., "Software quality model for maintenance software purposes", International Journal of Engineering Research and Technology, 2020, 13(1), pp. 158-162

[22]. ZahroturRohimah, et al., "Factors that Determine Customer Decisions in the Use of E-Payment in the Culinary Business", IJATCSE: International Journal of Advanced Trends in Computer Science and Engineering, Vol 8, No 7. 